of each particle was analyzed with a scanning electron microscope and an energy dispersive Xray microanalyzer.

In order to estimate the origin of aerosol particles, back trajectories of air parcels which arrived at the observation site were determined on $850 \mathrm{mb}$ charts. They were well correlated with the time changes of the number concentration of aerosol particles and also with the chemical composition of each particle.

In the cases when the aerosol particles seemed from trajectories to travel around with a slowly moving low pressure over the Norwegian Sea, the number concentration indicated low values for several days, and the chemical constituents of most particles were of marine origin, namely $\mathrm{Na}$ and $\mathrm{Cl}$.

Around the observation site the prevailing wind direction was from the southwest. The number concentrations for these cases indicated medium values with slight variation. The aerosol particles contained some soil elements although the primary elements were of marine origin.

On some days, aerosol particles derived from trajectories which passed over industrial areas in Europe arrived at the observation site. In this case the number concentration indicated high values, and the anthropogenic elements such as sulphate were detected frequently in aerosol particles.

(Received October 30, 1989)

\title{
CONCENTRATION OF ATMOSPHERIC CARBON DIOXIDE AT THE JAPANESE ANTARCTIC STATION, SYOWA (ABSTRACT)
}

\author{
Shuhji AokI', Takakiyo Nakazawa ${ }^{2}$, Shohei Murayama², \\ Masayuki TANAKA ${ }^{2}$, Takashi YamanOUCHI ${ }^{1}$, Sadao KaWAGUCHI ${ }^{1}$, \\ Masataka ShIObara $^{2}$, Masashi FuKabOrI ${ }^{3}$ and Haruta Murayama ${ }^{4}$ \\ ${ }^{1}$ National Institute of Polar Research, 9-10, Kaga l-chome, Itabashi-ku, \\ Tokyo 173 \\ ${ }^{2}$ Upper Atmosphere and Space Research Laboratory, Faculty of Science, Tohoku University, \\ Aramaki Aoba, Aoba-ku, Sendai 980 \\ ${ }^{3}$ Meteorological Research Institute, 1-1, Nagamine, \\ Tsukuba 305 \\ ${ }^{4}$ Faculty of Education, Yokohama National University, \\ 156, Tokiwadai, Hodogaya-ku, \\ Yokohama 240
}

Continuous measurement of the atmospheric $\mathrm{CO}_{2}$ concentration was initiated at Syowa Station in February 1984. Variation of $\mathrm{CO}_{2}$ concentration at this station can be divided into three components such as secular trend, seasonal cycle and irregular variation after removing contaminated data. The secular trend was variable with time. The increase rate of $\mathrm{CO}_{2}$ concentration was low from 1984 to 1986, but it became very high in 1987 and 1988. This change may be related to the 1987 ENSO event. The average rate of annual $\mathrm{CO}_{2}$ increase over the 5

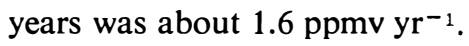

The average seasonal $\mathrm{CO}_{2}$ cycle showed minimum and maximum concentrations in midApril and early in October and its peak-to-peak amplitude was about $1.1 \mathrm{ppmv}$. The seasonal cycle including irregular parts was variable from year to year, but there was no indication of long-term expansion of the amplitude. 
The irregular $\mathrm{CO}_{2}$ variation observed, especially from February to August, had a high correlation with the air mass exchange by synoptic scale weather disturbances.

(Received December 6, 1989)

\title{
MEASUREMENTS OF THE ATMOSPHERIC MINOR CONSTITUENTS AT SYOWA STATION, ANTARCTICA, IN 1986 (II) (ABSTRACT)
}

\author{
Masashi FuKabori', Yukio MaKinO', Masayuki TANAKA", \\ Sadao KAWAGUCHI ${ }^{3}$ and Takashi YAMANOUCHI ${ }^{3}$ \\ ${ }^{1}$ Meteorological Research Institute, I-I, Nagamine, Tsukuba 305 \\ 'Upper Atmosphere and Space Research Laboratory, Faculty of Science, \\ Tohoku University, Aramaki Aoba, Aoba-ku, \\ Sendai 980 \\ ${ }^{3}$ National Institute of Polar Research, 9-10, Kaga 1-chome, \\ Itabashi-ku, Tokyo 173
}

Ground-based observations for the solar spectra were carried out to determine the column amounts of the minor constituents at Syowa Station, Antarctica in 1986. Solar spectra were measured within the spectral region from 400 to $5000 \mathrm{~cm}^{-1}$ by a Fourier transform infrared spectrometer (FTIR) whose resolution is 0.125 or $0.25 \mathrm{~cm}^{-1}$. Column amounts of the gaseous constituents were determined by comparing observed equivalent widths with theoretical calculations.

The total $\mathrm{H}_{2} \mathrm{O}$ obtained by FTIR observations agreed with the results of radiosonde soundings within the observational error. The temporal variation of the total $\mathrm{O}_{3}$ obtained by FTIR observations was quite similar to the result obtained by the Dobson spectrometer. Rapid increase of the total $\mathrm{O}_{3}$ accompanied by the stratospheric sudden warming was clearly observed on October 21. The temporal variations of the total $\mathrm{N}_{2} \mathrm{O}, \mathrm{CH}_{4}$ and $\mathrm{CO}_{2}$ were also found. We examined the relation between the variations of the total column amounts and the meteorological elements. Correlation between the total column amounts of $\mathrm{N}_{2} \mathrm{O}, \mathrm{CH}_{4}$ and $\mathrm{CO}_{2}$ and the thickness of tropospheric air mass was quite good.

(Received October 30, 1989)

\section{SULFUR COMPOUNDS OF PHYTOPLANKTON ORIGIN IN THE ATMOSPHERIC BOUNDARY-LAYER (ABSTRACT)}

\author{
Seizi Koga and Hiroshi TANAKA \\ Water Research Institute, Nagoya University, Furo-cho, \\ Chikusa-ku, Nagoya 464-01
}

\begin{abstract}
A box model was made to understand how dimethylsulfide (DMS or $\mathrm{CH}_{3} \mathrm{SCH}_{3}$ ), released from the ocean surface to the atmosphere, contributes to produce background aerosol particles
\end{abstract}

